DOCUMENTA

\title{
ESTUDOS SOBRE A GÊNESE DA PROFISSÃO NAVAL: CAVALHEIROS E TARPAULINS ${ }^{1}$
}

Norbert Elias

\section{Apresentação}

Norbert Elias (Breslau 1897-A msterdã 1990) morou na Inglaterra por quase quatro décadas. Chegou a Londres em 1935, dois anos após deixar o seu país, a Alemanha, em virtude da ascensão do nazismo. Quatro anos mais tarde aparecia na Basiléia, Suíça, a primeira edição de O Processo Civilizatório, a obra que várias décadas depois o consagraria como um dos cientistas sociais mais importantes do século XX. O texto que apresentamos aqui foi publicado em 1950 no British J ournal of Sociology e foi o primeiro artigo de Elias a vir a público depois da Segunda Guerra M undial, marcando o começo de sua lenta reintegração ao mundo das ciências sociais, do qual o exílio, a guerra e o holocausto tinham-no afastado. O texto inicia, também, uma longa série de trabalhos dedicada ao estudo da gênese do Estado nacional na Inglaterra (que, junto com a França e a Alemanha, seriam os universos empíricos principais de sua obra)2.

Elias planejava escrever três estudos sobre as origens e o desenvolvimento da carreira de oficial naval na Inglaterra nos séculos XVI e XVII, mostrando as relações entre a unificação política daquele país, o estabelecimento do domínio militar dos mares, as inovações tecnológicas que permitiram revolucionar a navegação e a profissionalização da Marinha (a transição entre o mundo dos corsários e o mundo dos oficiais navais, tornada célebre nas figuras de Francis Drake e J ohn Hawkins). O primeiro texto concentrar-se-ia na caracterização social dos membros dessa profissão nascente e nos mecanismos de seu recrutamento em dois grupos sociais diferentes. $\mathrm{O}$ segundo trataria das tensões e dos conflitos entre esses grupos, enquanto o último versaria sobre sua integração gradual e sobre o surgimento de uma hierarquia de oficiais navais unificada, combinando as funções e os métodos de treinamento de ambos os grupos. $O$ plano do trabalho incluía ainda comparações com o nascimento da profis- 
são naval na França, mostrando as relações entre o desenvolvimento e as características dessa profissão e os processos de formação desses dois Estados nacionais. Elias não chegou a completar a série. O segundo texto apareceu 27 anos depois do primeiro, em 1977, na revista holandesa De Gids (no 140, pp. 223-237) com o título “Drake en Doughty: De Ontwikkeling van een Conflict" (Drake e Doughty: O Desenvolvimento de um Conflito). O último dos estudos jamais foi publicado.

O primeiro texto da série, que ora publicamos, tem ainda o interesse de mostrar a posição de Elias diante de uma subdisciplina que, na época, consolidava-se nas ciências sociais: a chamada "sociologia das profissões". Contrapondo-se a uma visão restritivamente centrada no aparecimento de inovações tecnológicas ou no surgimento de capacidades individuais e coletivas, o que lhe interessa no estudo das profissões é sobretudo a articulação entre, de um lado, essas inovações e essas capacidades e, de outro, as transformações no mundo social mais amplo dentro do qual as novas profissões passam a existir e a ser reconhecidas. Por meio de uma fina sociologia histórica, Elias demonstra como se podem reconstruir grandes processos históricos a partir de objetos aparentemente menores, e sugere a possibilidade de se observar as configurações sociais de grande escala (como os Estados nacionais) por meio da análise das tensões que estruturam um micromundo social (como uma profissão).

Mana. Estudos de Antropologia Social agradece ao British J ournal of Sociology a autorização para republicar pela primeira vez este artigo3.

Profissões, despojadas de suas roupagens próprias, são funções sociais especializadas que as pessoas desempenham em resposta a necessidades especializadas de outras; são, ao menos em sua forma mais desenvolvida, conjuntos especializados de relações humanas. $O$ estudo da gênese de uma profissão, portanto, não é simplesmente a apreciação de um certo número de indivíduos que tenham sido os primeiros a desempenhar certas funções para outros e a desenvolver certas relações, mas sim a análise de tais funções e relações.

Todas as profissões, as ocupações, ou qualquer que seja o nome que tenham, são, de uma forma peculiar, independentes, não das pessoas, mas daquelas pessoas em particular pelas quais elas são representadas em uma certa época. Elas continuam existindo depois que esses seus representantes morrem. Como as línguas, pressupõem a existência de 
um grupo. E, se mudam, se novas ocupações surgem em uma comunidade, tais transformações não se devem simplesmente $a$ atos ou pensamentos desse ou daquele indivíduo em particular, nem mesmo de cientistas ou inventores. É a situação de mudança de uma comunidade inteira que cria as condições para o surgimento de uma nova ocupação e determina o curso de seu desenvolvimento.

Descobertas científicas, invenções e o surgimento de novas necessidades humanas e de meios especializados para satisfazê-las são, indubitavelmente, fatores que contribuem para o desenvolvimento de uma nova profissão. Mas nem as novas necessidades nem as novas descobertas são, por si só, sua fonte. Elas dependem umas das outras para seu desenvolvimento. As primeiras tornam-se diferenciadas e específicas apenas em conjunção com técnicas humanas especializadas4; estas, por sua vez, só aparecem e se cristalizam como ocupações tendo em vista necessidades potenciais ou reais 5 . O surgimento de uma nova ocupação, portanto, não se deve a um desses dois fatores especificamente, mas à interação de ambos. É essencialmente um processo de tentativa e erro ${ }^{6}$ no qual as pessoas procuram combinar técnicas ou instituições e necessidades humanas. Todo passo nessa direção é efetuado por indivíduos. O processo como tal, a gênese e o desenvolvimento de uma profissão ou de qualquer outra ocupação é mais que a soma total de atos individuais - tem seu modelo próprio.

Certos desajustes específicos, discrepâncias de um ou outro tipo entre instituições profissionais e as necessidades às quais elas servem, e tensões entre grupos de pessoas produzidas por tais discrepâncias impõem seus padrões sobre os indivíduos. Tudo isso, e não os indivíduos como tais, é que é o motor do desenvolvimento de uma profissão. $O$ ajustamento entre instituições e necessi dades em sociedades em constante mudança nunca é completo. Disparidades podem surgir ora em virtude de mudanças técnicas, ora em conseqüência de condições e exigências sociais. Quaisquer que sejam suas causas imediatas, elas criam dificuldades específicas, produzem atritos e conflitos, confrontam cada membro de uma profissão com problemas que não são por ele criados. No entanto, uma vez que ele esteja em uma profissão, esses problemas institucionais se tornam seus próprios problemas, essas dificuldades, sua próprias dificuldades, esses conflitos, seus próprios conflitos. E as soluções não estão inteiramente em suas mãos. Às vezes, mudanças nas condições sociais favorecem o ajustamento; outras vezes, retardam-no ou o impedem. Pode acontecer - e de fato aconteceu no início da história da profissão naval - que, por várias gerações, as pessoas se envolvam repetidamente em conflitos do mesmo tipo, lutem contra os mesmos problemas 
profissionais e, embora sabendo qual seria a solução ideal, sejam incapazes de colocá-la em prática. Em todos esses casos, os problemas são apresentados ao indivíduo pela rede de funções sociais na qual ele ingressa, com suas disparidades inerentes entre meios e fins. Impelido por elas, ele dá continuidade, com seus objetivos de curto prazo, a algo que ele não começou: o desenvolvimento a longo prazo de sua profissão.

Em estudos históricos, o desenvolvimento de profissões e outras instituições, com freqüência, aparece como um progresso suave e constante em direção à "perfeição" - a "perfeição" do nosso tempo. A atenção, em geral, volta-se mais para a face institucional - para a forma como ela se configura em um dado período, no seguinte e finalmente no presente - e menos para as relações humanas reais por trás dessa face. No entanto, somente considerando essas instituições parte de uma extensa rede de relações humanas, recuperando para a nossa própria compreensão as dificuldades e os conflitos recorrentes com os quais os indivíduos lutaram no interior dessa rede, pode-se compreender por que e como a própria estrutura surgiu e mudou de um período para outro. Os problemas não resolvidos, colocados para os homens de uma certa época pelas falhas de suas instituições profissionais, são, em outras palavras, uma parte tão essencial da história dessas instituições quanto as próprias soluções. Em retrospecto, estas só ganham sentido quando vistas em conjunto com aqueles. Se, por trás da face mais impessoal, alguém se vê frente a frente com pessoas lutando, geralmente em vão, para ajustar a estrutura institucional que herdaram, com todas as suas incongruências, ao que elas sentem ser suas próprias necessidades, então se dissipa a atmosfera que tão freqüentemente cerca velhas instituições nos livros de história, uma atmosfera de peças de museu. Nesse sentido, as pessoas do passado estão no mesmo patamar que nós; ou melhor, nós estamos no mesmo patamar que elas.

\section{II}

A profissão naval tomou forma em um tempo em que a M arinha era uma frota de embarcações a vela. Em muitos sentidos, portanto, o treinamento, as tarefas e os padrões dos oficiais navais eram diferentes daqueles de nosso tempo. Diz-se que o comando de um navio moderno, com seus equipamentos técnicos elaborados, requer uma mente cientificamente treinada. O comando de um navio a vela requeria a mente de um artesão. A penas pessoas iniciadas em tenra idade na vida no mar poderiam esperar dominar essa técnica. "Recrutá-los jovens" era um conhecido 
lema da antiga Marinha. Era normal que um rapaz jovem começasse sua futura carreira de oficial naval aos 9 ou 10 anos diretamente a bordo. M uitas pessoas experientes achavam que poderia ser tarde demais caso se começasse a ir a bordo somente aos 14 anos, não apenas porque quem o fizesse teria que se acostumar ao balanço do mar e superar o enjôo o mais rapidamente possível, mas também porque a arte de amarrar e dar nós em cordas, a maneira correta de subir ao mastro - segurando o ovém e não a enfrechadura - e várias outras operações mais complicadas somente poderiam ser aprendidas com uma prática longa e exaustiva. Para conhecer as embarcações a vela, as pessoas tinham que trabalhar, ao menos por algum tempo, com suas próprias mãos. Os livros tinham pouca serventia.

Ao mesmo tempo, todos os oficiais navais, ao menos do século XVIII em diante, se viam, e queriam ser vistos pelos outros, como caval heiros. Dominar a arte do marinheiro era apenas uma de suas funções. Naquela época, como agora, oficiais navais eram líderes militares que comandavam homens. Uma de suas funções mais importantes era lutar contra um inimigo, comandar sua tripulação na batal ha e, se necessário, abordar um navio hostil em uma luta corpo a corpo até a vitória. A demais, em tempos de paz como em tempos de guerra, oficiais navais freqüentemente entravam em contato com representantes de outros países. Esperavase que soubessem línguas estrangeiras, que agissem como representantes de seus próprios países com firmeza, dignidade e uma certa dose de diplomacia, e que se comportassem conforme as regras do que era considerado boa educação e civilidade. Em suma, um oficial da velha M arinha tinha que reunir algumas das qualidades de um artesão experiente e de um cavalheiro militar.

À primeira vista essa combinação de deveres pode não parecer surpreendente nem problemática. No curso do século XX, "cavalheiro" tornou-se um termo geral, vago, que se refere mais à conduta que à posição social. Pode-se aplicar a trabalhadores manuais, a mestres-artesãos e a nobres do mesmo modo. Durante os séculos XVII e XVIII, no entanto, tinha um significado social muito estrito. Tratava-se, durante o período de formação da profissão naval, da marca distintiva dos homens das classes altas e de al gumas porções das classes médias, uma designação que os diferenciava do restante do povo. Seu significado mudava de uma época para outra, com um certo lapso de tempo, de acordo com a composição da Câmara dos Comuns. No entanto, o que quer que significasse em uma certa época, aqueles que trabal havam com suas próprias mãos, fossem mestres-artesãos ou operários, eram sempre excluídos da 
posição de cavalheiros. Inclusive a mera suspeita de que tivesse feito trabalho manual em alguma etapa de sua vida era degradante para um cavalheiro.

A observação sempre citada de Pepys sobre as conseqüências de, entre os oficiais navais, os marinheiros nunca serem cavalheiros e os caval heiros nunca serem marinheiros era, portanto, mais que um jogo elegante de palavras. Era a expressão precisa de um dos maiores problemas práticos com os quais se defrontavam administradores e oficiais da Marinha no começo da história da profissão naval. Cavalheiros não podiam aprender a arte e a técnica de um marinheiro sem que se sentissem rebaixados perante os outros. M arinheiros experientes, por sua vez, que aprenderam seu ofício da única forma possível, começando cedo como aprendizes, não eram considerados cavalheiros; faltavam-Ihes ou julgava-se que lhes faltassem - qualidades como destreza, boa educação, liderança e tato diplomático, consi deradas atributos indispensáveis para as pessoas no comando de operações militares e que freqüentemente entravam em contato com oficiais estrangeiros, a maioria deles de origem nobre. Para o bom funcionamento de uma frota militar a vela, era necessário que seus oficiais tivessem algumas das qualidades tanto dos caval heiros militares quanto dos marinheiros. No entanto, como se poderia esperar conciliar, a bordo de um navio, funções profissionais e sociais que, em terra, pareciam totalmente incompatíveis?

A fusão das tarefas de um marinheiro com as de um caval heiro, como vemos mais tarde na história da profissão naval, não era, portanto, o arranjo simples e óbvio que parece ser quando se aplicam os conceitos sociais do nosso tempo. Era, outrossim, conseqüência de uma luta prolongada e de um processo de tentativa e erro que durou mais de um sécuIo. Da época de Elizabeth à da rainha Ana, e mesmo depois, os responsáveis pela $M$ arinha lutaram contra esse problema sem muito sucesso imediato. Condições especiais - reinantes apenas na Inglaterra e parcialmente na Holanda, dentre todos os países da Europa Ocidental - tornaram possível superar gradualmente essas dificuldades em alguma extensão. E tanto os obstáculos quanto os próprios conflitos deles resultantes, bem como a maneira como lentamente se resolveram, foram responsáveis por algumas das mais notáveis características da profissão naval inglesa. No entanto, para entender tudo isso, é necessário ter em mente as atitudes sociais e os padrões daquele período e visualizar os problemas inerentes ao crescimento da profissão naval tal como se apresentavam às pessoas daquela época, e não como parecem ser para nós, segundo nossas próprias referências sociais e nossos ideais. 
$\mathrm{Na}$ Idade M édia a Inglaterra não tinha uma Marinha no sentido próprio do termo. $O$ mesmo pessoal militar era usado em guerras em terra e no mar, as mesmas embarcações serviam para combates e para comércio ou pesca. Batal has navais, mesmo no Canal da $\mathrm{M}$ ancha, eram relativamente raras. Quando ocorriam, participavam delas exércitos reunidos em navios e que lutavam praticamente da mesma forma como lutavam em terra. Os marinheiros forneciam o transporte; os cavalheiros e seus seguidores guerreavam. A associação entre os dois grupos era puramente temporária. Dificilmente ocorreria a um nobre fidalgo assumir profissionalmente algumas das tarefas e das responsabilidades de um capitão de navio.

A situação mudou gradualmente na época das grandes descobertas. Durante aquele período, todos os países europeus com saída para o Atlântico - à exceção da Alemanha, enfraquecida por divisões internas - se lançaram, um após o outro, na luta pelo domínio das rotas marítimas recém-descobertas e das possessões ultramar. Para manter sua posição, a Inglaterra, assim como seus rivais, teve que desenvolver seus recursos marítimos. A força crescente de alguns de seus vizinhos ameaçava não apenas suas comunicações marítimas, mas também sua segurança interna. Os ingleses, por sua vez, ameaçavam com sua força crescente os países do outro lado do $C$ anal da $M$ ancha e dos mares hispânicos. O surgimento de um novo sistema de poder nos mares da Europa Ocidental e a espiral de rivalidade forçaram todos aqueles países a entrar em disputa; compeliram-nos a lutar, a se expandir, a se tornar o que chamamos de potências imperial istas e a continuar lutando até que um ou outro fosse derrotado e caísse. Não havia como escapar de seu impacto. Como seus rivais e seus aliados, a Inglaterra não tinha escolha senão expandir-se ou se tornar dependente de terceiros.

Sob a pressão dessa rivalidade marítima em constante expansão, muitas das necessidades desses países e das técnicas para satisfazê-las transformaram-se mais rapidamente que antes. Tornou-se necessário reorganizar a frota e as forças militares. Da mesma forma, em todos eles surgiram problemas similares de ajustamento. No entanto, como suas posições estratégicas e suas constituições políticas e sociais eram diferentes, o grau, a velocidade e o método de ajustamento variaram bastante.

$\mathrm{Na}$ Inglaterra, as forças militares, antes usadas indiscriminadamente para lutar em terra ou no mar, dividiram-se em forças terrestres e forças navais. A antiga frota a vela, usada para comércio ou combate conforme a ocasião, desenvolveu-se gradualmente em dois ramos mais especializa- 
dos: um de caráter principalmente comercial; o outro principalmente militar. Segmentos da frota e do Exército unidos e finalmente fundidos em um único formaram, no curso do tempo, um novo establishment especializado, uma esquadra militar conhecida como M arinha.

Ao mesmo tempo, esses dois movimentos gradualmente fizeram surgir uma nova profissão, a de oficial naval. A rivalidade de poder crescente trouxe o que se poderia chamar tradicionalmente de "divisão do trabalho". Em realidade, a diferenciação andou de braços dados com a integração, a especialização com a fusão, transformando não apenas o trabaIho, mas todas as funções sociais das pessoas. Não se tratava apenas de os marinheiros se especializarem para o serviço em um establishment militar e de os cavalheiros militares se dedicarem mais permanentemente à frota. O novo processo de guerra marítima criou a necessidade de haver pessoas que, em uma nova esquadra, fossem marinheiros e militares ao mesmo tempo.

No entanto, embora fosse difícil controlar os problemas técnicos criados pela condução de navios cada vez maiores, especiais para a guerra, enquanto as pessoas aprendiam lenta e arduamente a construir embarcações de dois ou três pavimentos com mais e mais armas, a solução dos problemas humanos criados por essas mudanças mostrou-se ainda mais difícil. Dois conjuntos de pessoas, marujos e caval heiros militares, que pertenciam a esferas bem diferentes da vida e que no passado haviam tido pouco contato profissional, foram forçados, como resultado desses acontecimentos, a colaborar mais estreitamente e por períodos mais longos que antes. Um padrão definido de trabalho em grupo envolvendo os dois conjuntos não podia existir nesse estágio a menos que uma autoridade externa fosse suficientemente forte para impô-lo, como na França e na Espanha. $\mathrm{Na}$ Inglaterra, em uma situação como aquela, lutas por status e disputas por posições eram inevitáveis. Unidos por circunstâncias além de seu poder, ambos os grupos tentaram preservar, em sua nova relação, seu modo de vida tradicional e os padrões profissionais aos quais estavam acostumados. Ambos falharam e ressentiram-se disto.

$\mathrm{Na}$ França e na Espanha, a crescente interdependência desses dois grupos produziu problemas muito similares. M as a solução foi-Ihes, em algum momento, imposta. Dificilmente se permitia que se desenvolvessem conflitos abertos entre marujos e cavalheiros. Eles eram suprimidos por regras estritas e inalteráveis. Os dois grupos, portanto, nunca se tornaram inteiramente integrados. Tampouco as funções militares e as náuticas se amalgamaram. Homens de distinção, nobres, continuaram sendo essencialmente cavalheiros militares e nada mais. Era impensável que 
eles passassem por um treinamento semelhante ao de um artesão; ou que artesãos se tornassem seus pares. Eles continuaram, de fato, até a Revolução Francesa e mesmo depois, a se ver e a se comportar mais ou menos como destacamentos especializados do Exército terrestre. M arujos profissionais continuaram a fornecer transporte a soldados. A distância social entre os dois grupos era tão grande que nem a hostilidade nem a fusão tinham lugar.

Por outro lado, na Inglaterra, cuja organização política e social era diferente, homens de ambos os grupos tornaram-se oficiais navais. A colaboração entre os dois segmentos era maior que na França e na Espanha. Tensões manifestas e hostilidades abertas eram mais freqüentes, e persistiram da época de Elizabeth à de Guilherme de Orange. Como resultado, surgiu gradualmente uma nova divisão, e uma nova hierarquia de deveres estendeu-se sobre ambos os grupos, cujas tarefas eram tanto militares quanto náuticas.

\section{IV}

A relação inicial entre os dois grupos era inequívoca; ambos sabiam quais eram os seus lugares. Durante parte do século XVI, os marujos profissionais ainda eram mestres indiscutíveis em seu próprio campo. $O$ rei, como outros donos de embarcações, geralmente deixava cada um de seus navios mas mãos de um capitão e seus companheiros. A principal corporação de capitães, a "Brotherhood of the most glorious and undivided Trinity" [Irmandade da gloriosíssima e indivisível Trindade], em Deptfordsur-Strand, ficava a cargo, na maior parte desse século, dos Entrepostos da Coroa em Deptford e da "M arinha Real" em geral. Era essa corporação, a Casa da Trindade, que selecionava os capitães para cada um dos navios do rei. Estes, por sua vez, levavam sua própria "turma", incluindo mestres-carpinteiros, oficiais encarregados da artilharia e cozinheiros. Eles formavam a tripulação permanente do navio.

O comandante, por seu turno, era "legitimamente escolhido por um general" 7 e "deveria escol her seu lugar-tenente" ${ }^{8}$. E no fim da jornada ambos deixavam o navio. Eles, os oficiais militares, eram designados temporariamente, conforme a ocasião.

No entanto, quando, no curso do século XVI, as operações militares no mar se tornaram mais freqüentes, e particularmente depois que as façanhas de corsários como Hawkins e Drake abriram para a juventude da Inglaterra novas perspectivas de fama e riqueza, jovens cavalheiros 
passaram a ser atraídos em número maior pela vida no mar9 ${ }^{9}$ Daquela época em diante, com breves interrupções, dois grupos de oficiais existiram na M arinha lado a lado, por mais de um século. Eles eram conhecidos por nomes como "capitães-de-terra" e "capitães-de-mar" ou "comandantes-cavalheiros" e "comandantes-marujos"10; os últimos, após a Restauração, ficaram conhecidos também como comandantes tarpaulins ou simplesmente tarpaulins ${ }^{11}$. Mas quaisquer que fossem seus nomes, naquela época as diferenças entre os dois grupos eram óbvias. As gerações posteriores, em geral, esqueceram ou não compreenderam o que pode ter parecido para elas um estado de coisas estranho e inexplicável. Os que viveram naquele tempo, contudo, o subentendiam; sempre podiam dizer a qual desses grupos um determinado oficial naval pertencia. Embora homens de ambos os segmentos desempenhassem na Marinha, ao menos nominalmente, as mesmas funções, ocupassem geralmente as mesmas posições e competissem, em certa medida, pelos mesmos cargos, eles diferiam não apenas em relação ao seu treinamento profissional, mas também à sua ascendência social.

Embora suas carreiras variassem bastante, os comandantes-marujos tinham algo em comum: eram artesãos ou "artistas". Todos começavam cedo como grumetes; passavam seu período de aprendizado a bordo, geralmente durante sete anos. Fazia pouca diferença se serviam em navios mercantes ou de guerra; também não importava muito se mudassem de um para outro mais tarde. No curso do tempo, com o devido consentimento da corporação, eles se tornavam capitães, lentamente e em etapas, caso não tivessem nada além de seus méritos, ou mais facilmente, se tivessem dinheiro e amigos que os ajudassem. Por casualidade ou por escolha, eles procuravam a designação de comandante de um dos navios do rei - no início, normalmente, de uma das embarcações menores como uma fragata ou talvez um navio mercante a serviço da Coroa durante uma guerra. E se eles fossem excepcionalmente bravos ou tivessem muita sorte, não havia coisa alguma, em princípio, que os impedisse de ascender à posição de almirante.

Os "comandantes-cavalheiros", por sua vez, chegavam ao comando basicamente da mesma maneira que outros oficiais militares. Não se cogitava que tivessem de passar por um período de aprendizado a bordo ou aprender o ofício de um marujo comum. Enquanto um comandante tarpaulin tinha que passar " por todos os cargos e todos os graus em um navio" 12 antes de se tornar um comandante a serviço do rei, para cavalheiros, ainda que novatos na frota, não havia na época de Elizabeth uma série de passos comparável ou um método regular de treinamento para a 
vida no mar. Todas as tentativas, durante o século XVII, de estabelecêlos fracassaram, principalmente porque seria muito difícil atrair jovens cavalheiros para a M arinha forçando-os a um treinamento incompatível com seu status e sua honra, ou seja, um treinamento com jovens artesãos ou pelo menos similar ao deles.

Em um número menor de casos, cavalheiros aprendiam a arte dos trabal hadores do mar compartilhando por um tempo a dura e rigorosa vida de marujos profissionais. Como M onson ou M ainwaring, tornavam-se corsários ou piratas ${ }^{13}$. Geralmente, tudo o que se exigia de um cavalheiro para preencher os requisitos para um encargo na Marinha eram algumas viagens marítimas como voluntário ou em uma situação similar, que não envolvia treinamento regular. Foi somente no século XVIII que um posto na carreira de jovens marinheiros, o de aspirante, tornou-se finalmente a base para o treinamento regular reservado a jovens cavalheiros. Naquela época, contudo, a fronteira entre os que eram e os que não eram vistos como cavalheiros já se havia deslocado ligeiramente no espectro social.

Durante o século XVII, portanto, muitos cavalheiros foram para o mar com pouca experiência, obtendo nomeações por intermédio de favores ou dinheiro. Eles eram, como escreveu M onson 14, "capitães que se davam ao direito de usar tal nome vinculando-o à máxima de que não precisavam de experiência". No mesmo sentido, Pepys, meio século mais tarde, ainda lutando sem muito sucesso contra o mesmo problema, observou, acerca da M arinha elizabetana, um tanto melancolicamente15:

\footnotetext{
“Observem... que em '88, embora houvesse um nobre almirante, eles se viram obrigados a fazer de dois simples tarpaulins, Drake e Hawkins, seus vice e contra-almirantes, apesar de haver muitos homens que pudessem ocupar tal posição na frota... M as é fácil perceber que serventia (além de mostrar sua coragem) teria sua inexperiência."
}

A diferença nítida entre o treinamento profissional e a carreira desses dois grupos de oficiais era, em outras palavras, intimamente ligada à diferença igualmente nítida entre seus antecedentes sociais. Os capitãesmarujos vinham, geralmente, do que se pode chamar de classes baixas e médias urbanas. Eles pertenciam à massa de pessoas comuns formada, naquela época, por comerciantes ricos, bem como por artesãos pobres. Os capitães-cavalheiros, por sua vez, eram cortesãos ou pelo menos homens que tinham conexões com a Corte. Como outras pessoas que se moviam na sociedade da corte, a maioria deles vinha da alta e da pequena nobrezas. Mesmo que fossem descendentes de famílias de classe 
média, como às vezes acontecia, a vida na Corte conferia a eles um status social especial. A final, membros da sociedade da corte formavam um grupo separado dos demais. Eles se distinguiam de integrantes de outros grupos sociais não apenas por sua influência real ou simulada e pelo poder derivado de um contato mais próximo com aqueles que governavam o país, mas também por suas maneiras e suas ambições, suas virtudes e seus vícios, e todo o seu modo de vida.

Assim, a divisão feita no século XVII entre capitães-cavalheiros e capitães-marujos na $M$ arinha era equivalente àquela feita na sociedade como um todo entre homens de classe e homens de origem humilde. Estava intimamente ligada àquela feita, particularmente em Londres, entre cortesãos e cidadãos. Em terra, essas classes de pessoas eram separadas por um abismo social. $\mathrm{Na}$ deflagração da guerra civil, a maioria dos cortesãos e dos cidadãos pertencia a campos opostos - e os marujos da Marinha juntaram-se aos cidadãos na proteção do Parlamento16. Eles viviam em mundos diferentes. Cortesãos dificilmente podiam admitir pessoas do povo em seus círculos de amigos, em pé de igualdade, quanto mais com intimidade, sem se rebaixar. Ainda assim, na M arinha, homens de ambos os grupos, cavalheiros e marujos, foram forçados a ter contato de maneira mais próxima. Lá, embora fossem de diferentes posições sociais, eles geralmente ocupavam postos de igual posição profissional; os papéis podiam até se inverter e os caval heiros tornarem-se subordinados daqueles que lhes eram socialmente inferiores.

Obviamente, essa situação fazia surgir tensões e conflitos. Para ver isto em perspectiva, devemos lembrar como as divisões sociais de então eram diferentes daquelas dos séculos XIX eXX. Riqueza, no século XVII, certamente contava muito; mas nascimento e criação ainda tinham precedência como fatores de determinação da posição social, e a casta impunha-se sobre a classe. No curso dos séculos XIX e XX, a vida social girava cada vez mais em torno de tensões e conflitos entre as classes baixas e médias. Tensões sociais correspondentes, certamente, não estavam ausentes durante o século XVII, mas ainda eram encobertas por aquelas entre as classes baixas e médias, de um lado, e as classes altas, de outro.

Do século XVII em diante, as camadas mais altas das classes comerciais aproximaram-se das classes altas; por outro lado, artesãos, pessoas envolvidas com trabalhos manuais, afundavam lentamente na escala social; e da última parte do século XVIII em diante, a principal linha divisória da sociedade - o principal eixo de tensão - moveu-se mais definitivamente para as porções comercial e industrial da população, dividindo-a em dois campos, as classes trabalhadoras e as classes médias. No 
século XVII, a fronteira entre as parcelas mais ricas e as mais pobres das classes comerciais ainda estava menos nitidamente desenhada. As diferenças no interior dessas classes, por maior que fossem, eram pequenas se comparadas àquelas que separavam todos esses grupos juntos das classes altas e particularmente da sociedade da corte.

\section{V}

A relação entre caval heiros e marujos na M arinha era altamente influenciada pela relação entre os estratos mais amplos da sociedade inglesa aos quais eles pertenciam. Cavalheiros que iam a bordo como oficiais naturalmente faziam o melhor que podiam para continuar a ter um estilo de vida ao qual estavam acostumados. Como de praxe, assumiam, em relação aos marujos, as mesmas atitudes de superioridade que marcavam suas relações com pessoas de posição social inferior ${ }^{17}$. Em suma, um abismo os separava do restante da tripulação.

A distância social entre os capitães-marujos e seus subordinados era, por comparação, pequena. Um capitão-marujo não se mostrava superior. Ele podia, como fazia Sir William Booth, dormir no convés "sem coisa alguma sobre ele exceto uma lona, que seus marujos estariam satisfeitos" 18 . Se ele levasse um jovem filho seu em uma jornada, podíamos ver o filho do capitão instruindo-se, divertindo-se e sendo castigado junto com as crianças dos mestres e do carpinteiro'19. E, a menos que o capitão tivesse mais dinheiro, as chances de seu filho na vida provavelmente não eram muito diferentes das de seus companheiros.

Também não havia grande diferença entre o status social de um comandante-marujo na M arinha e o de um comandante de um navio mercante. É verdade que, quando as classes baixas e médias se tornaram mais diferenciadas e a distância entre o serviço na M arinha de Guerra e o serviço na Marinha M ercante aumentou, os oficiais da primeira passaram a sair, geralmente, dos estratos sociais mais altos. No entanto, no fim do século XVII, ainda se podia encontrar na mesma família um filho que fosse capitão da M arinha e outro, capitão de um navio mercante20. Podiase ver oficiais da M arinha assumindo o cargo de capitão no serviço mercante, capitães de navios mercantes recebendo missões na M arinha. M esmo o imediato de um navio mercante podia dizer que "se considerava à altura de qualquer homem a serviço do rei" 21 .

Os antecedentes e as conexões das famílias dos comandantes-marujos seguiam o mesmo padrão. Alguns deles eram filhos ou irmãos de 
comerciantes prósperos. O capitão Thomas Best, por exemplo, que foi "treinado para o mar" da maneira usual, obteve o comando de um navio com a ajuda do pai, lutou em 1612, como um comerciante da Companhia das Índias Orientais, a outrora famosa batalha de Swally (na foz do rio Surat) contra uma força portuguesa superior, e como um homem bastante rico deixou o comércio na Companhia das Índias para ficar a serviço do rei. Guerras ou ameaças de guerra sempre levaram o governo a se valer de um considerável número de navios mercantes. Os armadores e os comandantes dos navios "então recrutados pelo governo" eram geralmente empregados para comandar os navios para a Coroa22. Esta era uma das muitas maneiras como comerciantes, armadores ou capitães comuns podiam se tornar capitães da M arinha. Sir Thomas Allin23, que nasceu em Lowestoft, parece ter sido originalmente comerciante e armador. $\mathrm{Na}$ deflagração da guerra civil, pôs-se, como sua cidade natal, do lado do rei. Em 1665, recebeu o título de Sir e foi designado almirante [Admiral of the Blue] sob o comando de lorde Sandwich. $\mathrm{Na}$ M arinha da Commonwealth, ex-comerciantes, armadores e comandantes desempenharam um papel ainda mais proeminente. Richard Deane, J ames Peacock, Nehemiah Bourne, Richard Badiley - todos eles, aparentemente, ganharam alguma experiência no mar como mercadores ou armadores antes de se tornarem capitães, vice-almirantes ou almirantes na Marinha da Commonwealth. Giles Penn, um capitão da M arinha, foi em outra época de sua vida cônsul para comércio inglês no M editerrâneo. Seu filho mais velho tornou-se um rico comerciante na Espanha; seu filho mais novo, William, nascido em Bristol em 1621, "participou com o pai, desde menino, de várias viagens mercantis" 24, tornou-se, na época, almirante da Commonwealth, serviu com a mesma função ao governo de Carlos II e recebeu o título de Sir por seus serviços.

Muitos outros comandantes tarpaulins saíram de um estoque de artesãos. Havia filhos de capitães de navios ou de mestres de artilharia que, no curso do tempo, seguiram os passos dos pais. Penn, por exemplo, ainda capitão, treinou e ensinou a escrever um certo George Leake, que fora “levado ao mar por seu próprio pai ainda bem menino e treinado para fazer qualquer trabalho, como Penn também o foi" 25 . George Leake tornou-se conhecido mais tarde como mestre de artilharia. Ele era pai do almirante Sir J ohn Leake.

A constituição do grupo social mais amplo do qual os comandantesmarujos provinham era, em muitos sentidos, diferente de qualquer grupo comparável em uma sociedade industrial completamente desenvolvida. Caso se apliquem os rótulos atuais - por exemplo, o de "classes médias" —, 
não se pode perder de vista o fato de que, primeiro, artesãos, pessoas que trabalhavam com suas próprias mãos, podiam ser encontrados não apenas nas camadas mais baixas desse grupo, mas também nas mais altas; segundo, as posições sociais que ocupavam se estendiam imperceptivelmente até o que poderíamos chamar de "classes baixas"; e, por fim, na grande maioria dos casos, não eram considerados nem se viam como caval heiros 26 .

Na maioria dos casos os comandantes-marujos não vieram, provavelmente, nem da seção mais rica nem da mais pobre do povo. O pequeno grupo de grandes comerciantes, pessoas como Sir Thomas Smith ou William Cockayne, da Companhia das Índias Orientais, certamente conhecia maneiras mais lucrativas de empregar seu tempo do que comandar um navio de guerra. Por outro lado, para um rapaz pobre, sem amigos ou família influentes, não era muito fácil ascender além das posições subordinadas a bordo. A fim de obter o posto de capitão, mais lucrativo, normalmente, era necessário ter ou um protetor benevolente ou dinheiro para pagar pela designação. A descrição detalhada que Edward Barlow27 fez dessa luta pelo avanço do posto de imediato ao de capitão durante a última metade do século XVII mostra como era difícil para um homem que começasse sem um protetor ou sem dinheiro obter o comando de um navio mercante ou ascender estando a serviço do rei.

No entanto, essa barreira monetária, certamente, não era insuperável. De fato, um bom número de pessoas que vieram de seções mais pobres das classes comerciais - das "classes baixas", como podemos chamá-las - ascendeu ao comando de navios de guerra. Dentre elas, o mais conhecido é, provavelmente, Sir Cloudesley Shovel 28 que, aparentemente, foi aprendiz de sapateiro antes de ir para o mar como criado de bordo sob o comando de Sir Christopher M yngs 29 e depois sob o de Sir J ohn Narborough ${ }^{30}$, dois outros comandantes tarpaulins que, no curso do tempo, tornaram-se almirantes. Às vezes, Shovel é lembrado como um caso excepcional, um homem que se tornou almirante e "ascendeu aos poucos" - que, em outras palavras, começou como um simples marujo. No entanto, embora qualidades excepcionais tivessem permitido que ele se tornasse almirante, até sua designação como capitão sua carreira correspondia ao percurso normal de um comandante tarpaulin. Dos seus colegas, Sir David Mitchell 31 começou como aprendiz em um pesqueiro de Leigh e depois foi imediato no comércio báltico; durante a segunda guerra holandesa, ele foi obrigado a entrar para a M arinha, notabilizouse, foi feito 2 o lugar-tenente em 1677, lugar-tenente em 1680 e capitão em 1684. De acordo com a Biographia Navalis ${ }^{32}$, ele "provavelmente não 
foi empregado durante o governo do rei J aime, tanto por sua conhecida aversão à fé católica quanto por ter sido um daqueles que primeiro recorreu ao príncipe de Orange". Caindo nas graças de Guilherme, ele se tornou em 1693 contra-almirante [Rear-Admiral of the Blue] e encarregado do guarda-roupa real. O vice-almirante J ohn Benbow começou, de acordo com alguns escritores, trabalhando para um barqueiro ${ }^{33}$ e, segundo outros, como aprendiz de açougueiro ${ }^{34}$. Ele fugiu para o mar e passou pelo treinamento normal de um marujo profissional. Em 1678, era contramestre; em 1679, capitão a serviço do rei; depois, e por muitos anos, como capitão, e talvez armador, em comando de um navio mercante; mais tarde, novamente na M arinha (1689), foi 3o lugar-tenente sob as ordens do capitão David M itchell na batalha de Beachy Head e, novamente, em 1692, na batalha de La Hogue. Em 1693 ele estava no comando de uma flotilha de navios lança-bombas e brulotes; serviu como contra-almirante em 1695 e, em 1701, como comandante-em-chefe nas Índias Ocidentais. Combateu com sucesso os franceses sob o comando de Du Casse em Cartagena em 1702, embora abandonado pelos outros navios de seu esquadrão, e morreu pouco depois em conseqüência de ferimentos. Ele foi descrito como "um simples marujo" que "falava e agia em todas as ocasiões sem nenhum respeito e com extrema liberdade" 35 . Seu fil ho foi, como ele, "treinado para o mar". Em 1701, foi para as Índias Orientais como 40 imediato 36 .

\section{VI}

Tanto as origens familiares quanto as carreiras dos comandantes-cavaIheiros eram bem diferentes. Alguns deles, como lorde Effingham e Howards, eram nobres, cortesãos e oficiais militares da mais alta posição. Eles assumiram o comando de exércitos navais como se estivessem à frente de outro comando militar qualquer, contando com marinheiros profissionais para lidar com todos os assuntos do mar.

Outros eram nobres e cavalheiros empobrecidos, de acordo com seus padrões, atraídos para o mar na esperança de restaurar sua fortuna pessoas como o almirante Thomas Cavendish ${ }^{37}$, que era, nas palavras de Campbell,

“[...] um cavalheiro descendente de uma família nobre de Devonshire e dono de um patrimônio bastante vasto o qual, homem espirituoso e de muito bom humor, ele dilapidou devido a seus gastos na Corte. Com isso, ele pôs na cabeça 
que iria restaurar sua fortuna destruída à custa dos espanhóis e, tendo isso em vista, construiu dois navios... e zarpou de Plymouth em 21 de julho de 1586" 38.

Outros vieram da pequena nobreza proprietária de terras. Filhos mais jovens ou filhos de filhos mais jovens, com um cortesão como protetor, pessoas como o vice-almirante Aylmer, segundo filho de Sir Christopher Aylmer de Balrath, do condado de M eath, que havia sido pajem do duque de Buckingham quando menino e que conseguiu, com sua recomendação, um lugar como voluntário em um dos navios do rei, tornandose lugar-tenente em 1678, comandante de uma corveta em 1679, capitão de um segunda classe em 1690, e vice-almirante e comissário da M arinha em 169439. Edward Russell, pai do almirante Russell, mais tarde conde de Oxford 40 , era irmão mais novo do primeiro duque de Bedford. 0 almirante George Churchill ${ }^{41}$, filho de Sir Winston Churchill ${ }^{42}$, era irmão mais novo de J ohn, primeiro duque de Marlborough. Sir Ralph Delaval, Sir George Rooke e muitos outros comandantes-caval heiros pertenciam à mesma categoria.

Outros eram filhos e parentes de pessoas que trabal havam para a Corte. O pai de Sir George Ayscue era criado de quarto de Carlos I. Edward Legge, pai de George Legge, mais tarde lorde Dartmouth, era o encarregado do guarda-roupa real de Carlos I; sua avó era irmã do primeiro lorde Buckingham.

Alguns poucos comandantes-cavalheiros eram filhos do que poderíamos chamar agora de "profissionais liberais". M as na maioria dos casos seus pais estavam a serviço do rei ou, de um modo ou de outro, em contato próximo com a Corte. Edward Herbert, pai do almirante Herbert, era advogado [Gentleman of the Long Robe]. Atuou como procurador-geral para Carlos I, associou-se no exílio ao duque de York e foi designado depois guarda-selos do rei. $\mathrm{O}$ almirante Killigrew era filho de um pastor anglicano, mas sua família tinha conexões com a Corte há mais de duas gerações. Seu bisavô fora camareiro da rainha Elizabeth, seu avô, cortesão e deputado. A irmã de seu pai, lady Shannon, era uma das amantes de Carlos II. Seu pai, dr. Henry Killigrew, era, na época da deflagração da guerra civil, capelão do Exército do rei. Depois se tornou capelão a serviço do duque de York. O próprio Killigrew era, por criação, cortesão e cavalheiro. Ele recebeu sua primeira missão depois de um curto período como voluntário.

Para ver a diferença mais claramente basta comparar a origem familiar de Killigrew com a de um comandante tarpaulin, Sir J ohn Berry, vicealmirante sob as ordens de lorde Dartmouth em 1683, cujo pai também 
fora pastor anglicano. O pai de Berry era um pastor do interior, aparentemente privado de seu sustento, saqueado e empobrecido durante a guerra civil, que morreu deixando uma viúva com nove filhos e pouco a que recorrer para viver. J ohn Berry, seu segundo filho43, que tinha 17 anos quando o pai morreu, foi para Plymouth, tornou-se aprendiz de um mercador, que era co-proprietário de vários navios, foi para o mar e aprendeu o ofício de marujo profissional do modo comum. Obteve com a ajuda de alguns amigos o posto de mestre em uma gal eota de dois mastros da M arinha Real e ascendeu, passo a passo, ao de lugar-tenente, capitão, vice-almirante e comissário da Marinha. Pepys o conheceu bem; deixounos, em suas notas sobre a expedição Tangier em 1683, registros das conversas que ele teve durante a jornada com Sir J ohn Berry e outro comandante tarpaulin de renome, Sir William Booth, capitão do navio, almirante da expedição. Como todos os demais, Pepys via Berry não como um cavalheiro, mas como um marujo profissional. Portanto, o almirante Killigrew e Sir J ohn Berry, embora fossem filhos de pastores anglicanos, vieram de fato de classes sociais bastante diferentes ${ }^{44}$ e pertenciam a diferentes grupos de oficiais da Marinha.

M uito ocasionalmente acontecia de homens de ascendência comum fingirem o papel e o status de comandantes-cavalheiros; mas, nestes casos, também, a proteção da Corte e a familiaridade com o aspecto e as maneiras dos cortesãos parecem ter sido essenciais. Pepys observou que, de acordo com Sir William Booth, "há quatro ou cinco capitães que ele sabe terem sido soldados de infantaria, companheiros de seus próprios soldados, e que agora julgam estar entre os nobres companheiros e os capitães-cavalheiros da frota”. E Pepys acrescentou: “[...] isto me faz crer que, por capitão-caval heiro, entende-se qualquer um que não seja um simples marujo [...]." 45

Temos notícia de poucos cavalheiros que aprenderam o ofício de marujo de forma semelhante à dos que lhes eram socialmente inferiores. Sir William Monson 46, por exemplo, conhecido comandante corsário elizabetano e autor de Naval Tracts, foi para o mar, provavelmente, em 1585, depois de alguns anos em Balliol, e aprendeu o ofício de marujo, por um tempo, da mesma maneira, árdua e penosa, como aprendia um navegador comum. Em 1587, assumiu o comando de um navio corsário, entrou para o serviço naval como voluntário, e pouco depois, sob a proteção do conde de Cumberland, tornou-se vice-almirante. Obteve sua licenciatura em Oxford em 1594, serviu em 1596 como capitão e, como capitão-debandeira na Marinha, recebeu o título de Sir depois de sua expedição para Cádiz. Ganhou fama e dinheiro quando apreendeu um navio na baía 
de Cezimbra. Ele tinha conexões familiares com a Corte tanto de Elizabeth quanto de J aime I. Seu irmão mais velho foi um dos chanceleres da rainha e um dos mestres adestradores de aves do rei. M onson combinou, de fato, o treinamento e a experiência de um marujo profissional com o de um cavalheiro-cortesão.

Mas híbridos desse tipo não eram muito numerosos mesmo na época de Elizabeth, quando a mobilidade social era comparativamente grande. Eles tornaram-se mais raros ainda sob o governo dos Stuarts. Pessoas falavam mais e mais abertamente de marujos e caval heiros como duas classes diferentes de oficiais navais. Depois da guerra civil, a consciência de classe era tão aguda que, nos círculos navais, e em certa medida no país inteiro, todos tomaram como natural a distinção entre comandantescaval heiros e comandantes-marujos.

Não se pode dizer com qualquer grau de precisão quantos oficiais navais pertenciam em um dado momento a cada uma dessas duas categorias ${ }^{47}$. A proporção alterou-se com as mudanças nas exigências da $M$ arinha e na política geral do governo. Mas pode-se dizer que, do fim do século XVI até o começo do século XVIII, ambos os grupos estavam representados em número suficiente para impedir que um deles dominasse o desenvolvimento da profissão naval e a moldasse sozinho de acordo com seus próprios padrões, suas tradições e seus interesses. Foram, de fato, o precário equilíbrio e a disputa recorrente entre esses dois grupos, refletindo o balanço de forças no país como um todo, que dominaram a história da profissão naval durante esses estágios iniciais de seu desenvolvimento.

\section{VII}

Em retrospecto, pode-se achar muito difícil, a princípio, visualizar uma profissão em que pessoas de diferentes posições sociais e diferentes treinamentos profissionais trabal hassem juntas como colegas e, ao mesmo tempo, lutassem umas com as outras como rivais.

No entanto, a profissão naval dos séculos XVI e XVII, certamente, não era a única em que dois grupos sociais e profissionais distintos, por um tempo, trabalharam e lutaram um com o outro. $O$ pessoal da nascente Força Aérea, por exemplo, foi recrutado no início do século XX, parcialmente entre homens com o perfil de aviadores e parcialmente entre oficiais militares. Neste caso também era necessário coordenar o trabaIho de dois conjuntos de pessoas de diferentes mentalidades e, em certa 
medida, de diferentes antecedentes sociais. $\mathrm{M}$ as a disputa entre eles era pequena, e a rivalidade, reprimida.

As situações desse tipo não estão confinadas à história das profissões militares. Hoje, por exemplo, dois grupos com diferentes antecedentes sociais e qualificações profissionais estão dividindo o gerenciamento de indústrias estatais. Pessoas a cargo dessas indústrias são recrutadas parcialmente nas classes médias e parcialmente entre homens saídos da classe trabalhadora.

Não seria difícil encontrar exemplos desse tipo no passado e no presente. De fato, uma fase similar, de antagonismo inicial e luta por posições entre grupos rivais, pode ser encontrada no início da história não apenas das profissões, mas de quase toda instituição. Quando se tenta elaborar uma teoria geral da gênese das instituições é provavelmente necessário considerar que o conflito é uma das características básicas de uma instituição nascente.

$M$ ais ainda; pode-se dizer que batalhas similares por status e lutas por posição, mais longas ou mais curtas, conforme o caso, podem ser encontradas sempre que indivíduos, inicialmente independentes, se reúnem em um grupo, ou grupos menores em maiores. Nesse sentido, as tensões e os conflitos entre soldados e marinheiros, entre cavalheiros e marujos na história da profissão naval podem servir como modelo simples para outros conflitos e outras batal has mais complexas na história da humanidade. Tratava-se de tensões de grupo e conflitos institucionais, ou seja, inerentes à situação de grupo desses homens e causadas pelo padrão institucional de suas relações e suas funções, distintas de tensões pessoais primárias e conflitos entre pessoas causados, por exemplo, por tendências paranóicas ou sádicas ou, mais comumente, por conflitos internos dos indivíduos. Por essa razão, reproduziram-se durante muitas gerações embora os indivíduos tivessem mudado.

O relato detalhado dessa disputa e do surgimento gradual de uma profissão mais unificada deve levar a dois estudos separados. No entanto, o estudo das características sociais desses dois grupos já fornece algumas pistas dos problemas que tinham de ser resolvidos antes que essa luta pudesse chegar ao fim, e das dificuldades que se puseram no caminho.

O problema se fez sentir, tanto quanto sabemos, primeiramente, na época de Elizabeth. J á em 1578, durante sua viagem de circunavegação, Drake falou de disputas entre caval heiros e marinheiros e salientou que era necessário, para os dois grupos, trabalhar conjuntamente. M ais de um século depois, em 1683, Pepys, em uma discussão com Sir William Booth e outros sobre o mesmo tema, escreveu ${ }^{48}$ que eles 
“[...] concordam que cavalheiros deveriam ser trazidos para a M arinha por serem homens mais sensíveis à honra que os de origem humilde (embora aqui caiba examinar se grandes ações em termos de honra não foram feitas por simples marujos, e ações de pouco valor, por cavalheiros), mas teriam de ser educados pelo tempo no mar [...]. E além do bem que o cavalheiro faria ao rei e à $M$ arinha, por seus amigos na Corte, ele abraçaria a causa dos marujos, saberia o que eles mereciam e os amaria como parte de si mesmo. Por sua vez, os marujos seriam levados a amá-lo ainda mais que a um igual devido à sua qualidade, sendo o cavalheiro, no entanto, seu companheiro na vida e nos trabalhos do mar."

E em 1694 o marquês de Halifax, novamente, se referiu, em seu Rough Draught of a New Model at Sea, à "presente controvérsia entre os cavalheiros e os tarpaulins"; ele ainda se perguntava "entre que tipos de homem os oficiais da frota devem ser escolhidos [...]"49, e opinou que "deve haver uma mistura na M arinha entre cavalheiros e tarpaulins" 50.

Da época de Drake à de Halifax, um compromisso entre os dois grupos e uma integração de ambos parecia para muitas pessoas a solução ideal. No entanto, como em muitos outros casos, ninguém sabia ao certo como esse ideal seria atingido. Nem Drake, nem Pepys, nem Halifax produziram um esquema durável por meio do qual isso pudesse ser posto em prática. Se os marujos não eram caval heiros e os cavalheiros não eram marujos, como seria possível imaginar um esquema unificado de treinamento e promoção de oficiais navais satisfatório para ambos os grupos? 


\section{Notas}

1 Esses estudos são baseados em pesquisa feita há al guns anos pela Social Research Division da London School of Economics. Agradeço imensamente a $\mathrm{H}$. L. Beales por seus conselhos e incentivo.

2 Fazem parte dessa série os artigos que tratam das relações entre o desenvolvimento do esporte e o processo de parlamentarização na Inglaterra. Sobre isso, ver J osé Sergio Leite Lopes, “Esporte, Emoção e Conflito Social”, M ana. Estudos de Antropologia Social, 1(1):141-165, 1995.

3 As referências bibliográficas não figuram aqui no formato usual de $M$ ana, sendo em vez disso apresentadas em notas e segundo sua formatação original, como no texto em inglês.

4 “'Eu venderei livros para que suas crianças os possam ler.' O chefe disse 'obrigado pelo presente" e levantou as mãos saudando, como se deve fazer sempre que alguém oferece algo no Limbo. M as então ele abaixou as mãos e disse com um tom de impaciência: 'Não é como o homem que deu ao vilarejo um tigre e depois a arma com a qual atirar nele?' Um urro de aprovação... veio dos que o ouviam. 'N ós não temos livros e, portanto, não temos que ler.'” De Aubrey M enen, The Prevalence of Witches, p. 94.

5 A. M. Carr-Sauders e P. A. Wilson, The Professions, Oxford, 1933, p. 297, onde esta interdependência foi observada, embora com grande ênfase em um fator: o progresso da pesquisa.

6 M. Ginsberg, The Work of L. T. Hobhouse, in J . A. Hobson e M. Ginsberg, L. T. Hobhouse: His Life and Work, London, 1931, p. 158: “O método mais comum de operação em grandes grupos é estritamente comparável ao que em psicologia se chama tentativa e erro. A acomodação de propósitos parciais uns aos outros sua inter-relação e sua correlação - é feita por meio de uma série de esforços de ajustamento nos quais o observador externo pode por acaso detectar um princípio que os próprios agentes não poderiam formular. Há, em suma, um ajustamento ponto por ponto, mas não existe um objetivo abrangente ou que seja resultado de um acordo."

7 Sir William Monson, Naval Tracts, ed. por M. Oppenheim, 1913, vol. IV, p. 14.

8 Idem, p. 15.

9 “M irem Drake. Sua reputação é tão grande que seus compatriotas juntaram-se em bandos a ele para compartilhar da pilhagem." - Cal. S. P. Ven., 20 de agosto de 1588 . 
10 O termo "comandante", durante todo aquele período, referia-se à função real das pessoas, não a uma posição específica. Podia ser aplicado a qualquer pessoa no comando de um navio.

11 "Tarpaulin" [no original], Iona alcatroada, era naquela época o que se podia chamar de capa do marujo comum. Tinha vários usos. Podia ser empregada como cobertura durante a noite; podia proteger do sol e do vento ou servir como capa de chuva. Assim, de nome daquilo que usavam como vestimenta, "tarpaulin" [lona] tornou-se a alcunha dos marujos. Como se tratava de uma palavra grande e pouco prática para um apelido, ao longo do tempo converteu-se em pura e simplesmente "tar".

12 Monson, Naval Tracts, vol. IV, p. 24.

13 M onson chamou a atenção para a diferença entre a autoridade dos comandantes da M arinha Real, que "recebiam o poder de um general", e a dos "comandantes-corsários", que, como reconhecimento, recebiam apenas reprimendas. Os últimos, fossem marujos profissionais ou cavalheiros, estavam exatamente na mesma posição dos capitães e de outros marinheiros. Todos eles saíam "à sua própria sorte" e não recebiam pagamento. "Portanto, eles sujeitarão o comandante", escreveu M onson, que obviamente falava tendo em vista sua própria experiência, “às mesmas condições, em sua rotina, [...] às quais eles estão sujeitos. Sua autoridade é um pouco maior que a do capitão de um navio pirata" (N aval Tracts, vol. IV , p.17). A diferença entre corsários e piratas não era, naquela época, tão grande quanto nos possa parecer. Os primeiros saqueavam, queimavam e destruíam navios estrangeiros com a permissão da rainha ou do rei; os últimos, sem permissão. O capitão J ohn Smith, em sua General History of Virginia, 1629, cap. 28, citou uma variedade de oficiais navais elizabetanos que, no tempo do rei J aime, por falta de emprego, porque "eram pobres e não tinham coisa alguma", tornaram-se piratas e foram "piedosamente perdoados" quando o rei precisou novamente de oficiais experientes para sua M arinha.

14 Monson, Naval Tracts, vol. IV, p. 14.

15 G. Pepys, Naval Minutes, ed. por J .R. Tanner, N.R.S., 1926, p. 119.

${ }^{16} \mathrm{~J}$ ournal of Sir Simonds D'Ewes, ed. por W. H. Coates, New Haven, Yale University Press, 1942, p. 348, 10 de janeiro de 1641 (1642):"Navegadores e marinheiros propuseram-nos deixar que se juntem a nós amanhã para defender o Parlamento por via naval com mosquetes e outras armas em várias embarcações, e nós aceitamos." Um panfleto, "O protesto do marujo [...] acerca dos movimentos na Câmara do Parlamento em Westminster, a 11 de janeiro de 1642", também indica quanto os marujos da Marinha consideravam a causa do Parlamento, e a da Cidade de Londres, sua própria causa: “[... ] com os rumores sobre uma possível dissolução da grande Corte, sabendo que a felicidade deste reino consiste em seus serviços, e lembrando as palavras do arcebispo Cranmer, um mártir de saudosa memória, que disse: 'que o M inistério da Guerra defenda a Inglaterra quan- 
do não houver Parlamento', nós, que vimos e ouvimos toda a cidade em armas, todos transformados em soldados inexperientes, com toda a presteza que nos foi possível, servimos, na água, à sua marcha e juntamos nossa munição aos mosquetes citadinos à entrada da Câmara (o Templo de nossa segurança) para o terror (esperamos) de todos os Papistas e dos Inimigos do País [...]. Nós, que sempre vamos a terras estrangeiras, podemos dizer, melhor do que ninguém, que nenhum governo sobre a Terra é comparável a este; [...] Vejam as lamentáveis desorientações na França, na Espanha e na Alemanha pela falta de algo assim [...]. Agora o reino está envolvido em uma guerra civil e um poderoso Exército de Papistas (e A teus) contrários às conhecidas Leis da Terra está em Armas contra o Parlamento para, se pudessem, destruí-lo e, assim, esmagar as Leis Tradicionais e o POVO da Inglaterra, fazendo de nós todos escravos em nossa religião, nossas imunidades e nossos privilégios. Compete a nós, que somos marujos, movermo-nos e não nos precipitarmos, porque nós, e apenas nós, conduziremos a Frota de navios que defende e sempre defendeu o Reino da invasão estrangeira [...]".

Sir J ohn Laughton, em um ensaio, "History and Naval History" (publicado em Naval and M ilitary Essays, Cambridge, 1914, pp. 4 e ss. ), em que reclamava, com fundamento, que a influência sobre a Inglaterra atribuída à M arinha em estudos históricos era normalmente confinada às batal has vencidas no mar, e no qual afirmava que, na verdade, tal influência foi muito mais ampla, deu o seguinte exemplo, entre outros (p. 7): “Sabe-se, creio eu, que, na Guerra Civil do século XVII, a M arinha manteve-se fiel ao Parlamento, mas, como não lutou em batalha alguma, o proveito para a Assembléia foi considerado insignificante, desprezível. Somente depois de mais de duzentos anos, o dr. Gardner nos mostrou que a Marinha foi, na verdade, o fator determinante da luta; no entanto, mesmo Gardner não julga necessário examinar por que a M arinha ficou do lado do Parlamento."

17 Richard Gibson, um funcionário da M arinha na época de Pepys e um ardoroso partidário dos marujos, comparou em um memorando (publicado em Life and Works of Sir Henry Mainwaring, N.R.S., 1922, vol. II, pp. Ixxxvi e ss.) as atitudes e as qualificações de oficiais-cavalheiros e oficiais-marujos. Embora obviamente parcial, a comparação é, em alguns aspectos, bastante instrutiva.

“[...] um caval heiro é posto no comando de um (suponhamos) navio de 4a classe com uma tripulação de 200 homens; ele trará cerca de 20 homens para o navio - criados, alfaiates, barbeiros, músicos, parentes arruinados, cavaIheiros voluntários ou conhecidos, acompanhantes. Todos serão acomodados como imediatos, aspirantes, contramestres, mestres corneteiros, timoneiros etc. e muito provavelmente receberão pagamentos equivalentes [...]. Os capitães-cavalheiros trazem tanto consigo a bordo, na opinião do bispo William, porque a Providência fez o homem para viver em terra, e é a necessidade que o conduz ao mar. Quando ocorre o contrário, um marujo no comando de um navio de 4 a classe com 200 homens não tem nada nem ninguém a não ser os que têm o mar por profissão [...]".

"Um capitão-marujo exige menos do navio para sua acomodação".

"Um capitão-cavalheiro reclama a parte superior para sua grandeza, o tombadilho de popa para os que vieram com ele etc." 
“Um marujo está familiarizado com seus homens, conversa com seus homens em serviço, fica no convés a noite toda enfrentando o mau tempo, dá a alguns um pouco do que estiver bebendo."

"Um cavalheiro tem um sentinela na porta de sua grande cabine (para manter o silêncio) e com freqüência castiga seus subalternos por não aparecerem imediatamente quando ele toca sua sineta durante a noite [...]".

18 G. Pepys, Tangier Papers, ed. por Edw. Chappell, N.R.S., 1933, p. 135.

19 Ramblin' J ack, the J ournal of Captain J ohn Cremer, 1700-1774, London, 1936, pp. 45 e ss.

20 Idem, pp. 33 e ss. O pai de J ohn Cremer ganhou a vida como capitão de navio mercante. $\mathrm{O}$ irmão de seu pai era capitão na M arinha. Seu sobrinho, um lugartenente da M arinha. Sua mãe era filha de um mestre-cordoeiro "que vivia luxuosamente". A irmã de sua mãe era casada com "o capitão Maine, tio do almirante Maine". Ele foi criado por uma tia que primeiro foi casada com um capitão (sem especificação), depois com um almoxarife na Alfândega cujo sobrinho era um capitão naval. Sua avó, viúva de um mestre-cordoeiro, casou-se uma segunda vez com um "velho cavalheiro que tinha dois filhos, lugares-tenentes na M arinha, e três filhas, uma das quais era casada com um capitão de um navio da Companhia das Índias, outra com um capitão de um navio mercante e a terceira com um rico fazendeiro".

${ }^{21}$ J ournal of Edw. Barlow, col. por B. Lubbock, London, 1934, II, p. 328.

22 G. Penn, M emorials of the Professional Life and Times of Sir William Penn, 1833, vol. I, p. 3.

${ }^{23}$ Artigo em Dict. of Nat. Biography.

${ }^{24}$ G. Penn, Memorials, p. 5.

25 Pepys, Tangier Papers, p. 288.

${ }^{26}$ A camada mais alta das classes comerciais era representada, naquele período, pelos governadores e pelos diretores das grandes companhias de comércio, especialmente da Companhia das Índias Orientais. Na carta de 1600 da rainha Elizabeth, nem o governador nem qualquer um dos 24 diretores desta Companhia foi designado "cavalheiro"; na de J aime I, o governador era um aristocrata, mas os 24 diretores ainda eram cidadãos comuns. Na carta de 1661 de Carlos II, o governador e onze dos 24 diretores eram chamados de "knights" [ "cavaleiros", aos quais corresponde o título de Sir], um diretor era nobre, outro era chamado de "excelentíssimo", e o restante, de "cavalheiros" (India Office Library, Quarto of Charters apud W. W. Hunter, History of India, 1900, vol. II, p. 188). Este é um exemplo da transformação no curso da qual a divisão entre as classes altas e médias-altas tornou-se menos pronunciada, enquanto a distância entre as últimas e as classes baixas evidenciou-se mais. 
27 J ournal of Edw. Barlow, transcr. e ed. por B. Lubbock, London, 1934.

28 c. 1650-1707. A famosa história de como ele nadou quando menino com importantes documentos na boca pela linha de fogo do inimigo é com toda probabilidade apócrifa. Nem os textos em homenagem a Shovel logo após sua morte, nem Campbell, em seu Life of the British Admirals, da metade do século XVIII, a mencionam. J . Charnock, em sua Biographia Navalis, do fim do século XVIII, tratou-a como autêntica. $M$ ais tarde ela foi aceita e freqüentemente repetida provavelmente como um exemplo do que se considerava ser sua "extraordinária" carreira. De acordo com a Biographia Navalis, ele foi lugar-tenente no esquadrão de Sir J ohn Narborough em 1674 e notabilizou-se na luta contra os corsários de Trípoli por queimar os navios do dei no porto. No mesmo ano ele foi feito capitão de um quinta classe. Como muitos outros comandantes tarpaulins, discordou da política de J aime II e fez pouco progresso na carreira depois de 1688. Ele destacou-se na Batalha de Bantry Bay e pouco depois recebeu de Guilherme de Orange o título de Sir. Na batalha de La Hogue, foi o primeiro a penetrar na linha do inimigo e foi posto no comando conjunto da frota com o almirante Killigrew e Sir Ralph Delaval. Em 1705 era comandante-em-chefe da frota britânica. Em 1707, em seu retorno da tentativa malsucedida em Toulon, foi afundado perto das ilhas Sicília. Sua mulher era viúva de seu antigo chefe e protetor, Sir J ohn Narborough. Sua filha casou-se com lorde Romney.

29 1625-66. Sob a data de 13 de janeiro de 1666, Pepys escreveu em seu diário: "Seu pai [o pai de M yngs] sempre foi e atualmente é um sapateiro, e sua mãe, filha de um barqueiro do qual ele freqüentemente se orgulhava." O Dict. of $\mathrm{N}$ at. Biography acrescenta que "esta afirmação é certamente exagerada se não inteiramente falsa. Seus pais eram de famílias prósperas no norte de Norfolk. Seu pai [...] parece ter sido um parente próximo, se não filho, de Nicholas Mynnes, o representante de uma boa e tradicional família de N orfolk. Sua mãe, Katherine Parr, era filha de Christopher Parr, dono de propriedades." Controvérsias desse tipo, particularmente em relação aos comandantes-marujos dos séculos XVI e XVII, são encontradas com freqüência em biografias de oficiais navais. Portanto, expressões como "boa família" ou "dono de propriedades" ajudam relativamente pouco na tarefa de elucidar o status social de uma família, a menos que sejam acompanhadas de um relato mais detalhado a respeito do tamanho e da característica de tal propriedade, da ocupação de seu dono e, sobretudo, do status social atribuído a um homem e a seus parentes por seus contemporâneos. Qualquer que seja nossa opinião, uma família do século XVII somente era uma "boa família" se fosse vista como tal por seus contemporâneos. A esse respeito, não pode haver muita dúvida acerca do status de Sir Christopher Myngs. Em sua própria época ele sempre foi visto como um homem de ascendência comum. Na Marinha, era conhecido como comandante tarpaulin. Ele era, de fato, um dos poucos tarpaulins que permaneceram em boa conta após a Restauração. Em 1664, içou sua bandeira como vice-almirante de um esquadrão do Canal da Mancha; recebeu o título de Sir em 1665; mas em 1666, em seu funeral, como Pepys observou, ninguém da alta sociedade esteve presente, à exceção de Sir William Coventry. 
30 1640-88.

31 1650(?)-1710.

32 J. Charnock, Biographia Navalis, 1794, vol. II, p. 105.

33 Biographia Britannica, 1747, vol. I, p. 179.

34 Dict. of $\mathrm{N}$ at. Biography.

35 Campbell, Lives of the Admirals, 1750, vol. IV, p. 233: “[...] no reinado de Carlos II ele era armador e comandante de um navio chamado Fragata Benbow [...]. Era considerado pelos comerciantes um comandante audacioso, bravo e ativo [...] homem algum era mais [...] respeitado pelos comerciantes na Bolsa que o capitão Benbow [...]. A diligência e a atividade do capitão Benbow o recomendavam para servir ao [...] rei Guilherme, a cuja benevolência, fundada em um senso justo do mérito de Benbow, ele devia o fato de ter sido logo promovido a oficial-general."

36 Idem, p. 234.

37 1560-92.

38 Life of the British Admirals, vol. I.

39 J. Charnock, Biographia Navalis, vol. II, p. 35.

40 1653-1727.

41 1654-1710.

42 1620-88, batizado com o nome de seu avô materno, Sir Henry Winston de Standiston. Winston Churchill, recebeu o título de Sir em 1663, depois se tornou comissário da Court of Claims da Irlanda e um dos fiscais do Green-Cloth.

${ }^{43}$ Campbell, Life of the Admirals, 1750, vol. III, pp. 279 e ss.

44 Um século depois, da segunda metade do século XVIII em diante, o status de caval heiro passou a ser reconhecido a clérigos e a seus filhos mais ou menos como algo natural. No século XVII e no início do século XVIII, treinamento e funções profissionais apenas não conferiam às pessoas o status de cavalheiro. $O$ alto clero, especialmente os bispos, eram considerados cavalheiros porque essas posições eram geralmente reservadas a pessoas nascidas nas classes de cavalheiros. Os clérigos mais pobres estavam na mesma posição dos artesãos, comerciantes e operários, porque vinham, na maioria, do povo e viviam como tal. Outras ocupações que podemos chamar de profissões liberais - por exemplo, a de advogados - eram igualmente divididas; elas não faziam parte do que as gerações posteriores passaram a chamar de "classes médias liberais". Quanto à profissão naval, o 
que era anômalo não era tanto o fato de que recrutasse seus membros em grupos de diferentes seções da sociedade, mas o fato de que homens dos estratos mais baixos podiam ocupar as mesmas posições e ascender aos mesmos patamares que aqueles dos mais altos.

45 Pepys, Tangier Papers, N.R.S., 1935, p. 121.

46 Sir William M onson, Naval Tracts, ed. por M. Oppenheim, N.R.S., 1902, vol. I, General Introduction.

47 R. Gibson deixou uma lista de todos os comandantes tarpaulins que, do tempo de Elizabeth até seu próprio tempo, se tornaram oficiais-generais. A parentemente, sua lista não inclui comandantes tarpaulins que se tornaram oficiaisgenerais sob o governo de Guilherme III. Gibson menciona seis almirantes, nove vice-almirantes e quatro contra-almirantes (Life and Works of Sir Henry Mainwaring, N.R.S., 1922, vol. II, p. xc). Parece razoável assumir que entre comandantes, capitães etc. a proporção de marujos profissionais fosse geralmente maior que entre almirantes.

48 Pepys, Tangier Papers, N.R.S., 1935, p. 121.

49 P. 7.

50 P. 22.

Palavras-chave Profissões, Inglaterra Séculos XVI-XVII, Marinha
Key words Professions, England XVIth XVIIth Centuries, Navy 